\title{
The lexical semantics and syntax interface of anticausative alternations in Kiwoso
}

\author{
Aurelia Mallya \\ Department of Foreign Languages and Linguistics, University of Dar es Salaam, Tanzania \\ E-mail: mallya.aurelia@udsm.ac.tz
}

\begin{abstract}
This paper examines argument alternation constructions in the Bantu language, Kiwoso. The data demonstrates that alternation is constrained by selectional properties of a root and its combination with different functional heads, which is language specific. The findings establish that external arguments of anticausative, passive and middle alternations are distinct in terms of syntax and semantics. The data indicates that external arguments appear as DPs in causative alternates but in anticausative, passive and middle sentences they surface as PPs, albeit with different interpretations. In passives, the PPs are introduced by a $n a$-phrase and express event participants, while in anticausatives and middles they are introduced by a kophrase which denotes event modifiers. It is also established that anticausative, passive and middle verb constructions are related in that their sole subject argument is the object argument of their causative (transitive) variants.
\end{abstract}

Keywords: Anticausative; causative; middle; Kiwoso; Bantu.

\section{Introduction}

This paper examines the characteristic of change of state verbs in Kiwoso ${ }^{1}$ in relation to the (anti-)causative alternation and other related types of transitivity alternations such as passives and middles. It examines the suitability and applicability of the syntactic decomposition approach as postulated in Alexiadou, Anagnostopoulou, and Schäfer (2006, 2015) and Alexiadou (2010) on the account of various verbal argument alternations and their interaction with causation, argument realization and event semantics in Kiwoso.

Scholars have established that across languages anticausative, passive and middle constructions are morphosyntactically interrelated alternations, which are semantically diverse (Schäfer 2009). This area has not been adequately researched in African languages. The present paper aims to contribute to the on-going debate on the interrelated aspects, namely causation, argument realization and event semantics employing new data from a Bantu

\footnotetext{
${ }^{1}$ Kiwoso is classified as one of the languages under zone E, code number 60 (chagga group). Kiwoso is specifically coded E621D. This language is spoken in the north-eastern part of Tanzania.
} 
language, Kiwoso. The paper seeks to offer a systematic and unified analysis of anticausative, passive and middle verb constructions in order to establish their shared morphosyntactic characteristics.

In studies on Bantu languages, considerable attention is given to the causative verbal suffix is- (Hyman 2003; Mchombo 2004; Lusekelo 2008). The process of morphological causativization entails that a verb adds a causer argument, having a coercive, assistive or permissive interpretation depending on the discourse contexts, as examples in (1) from Kiwoso illustrate ${ }^{1}$.
a. wa- le- dem- is-a wa-na 2SM- PST- cultivate- CAUS-FV 2-child "They made the children cultivate."
b. wa-le-tol-is-a mu-na ngaraja 2SM-PST-cross-CAUS-FV 1-child 9bridge "They assisted/helped the child to cross the bridge."

However, the causative meaning of the suffix -is- in Bantu languages exemplified in (1) has no relationship with the issues of causation addressed in this paper. This paper examines the causative syntax in relation to the causative and anticausative uses of a verb which exhibit argument alternation properties, as demonstrated for English and for Kiwoso in (2) and (3), respectively.

(2) a. Grace broke the window

b. The window broke

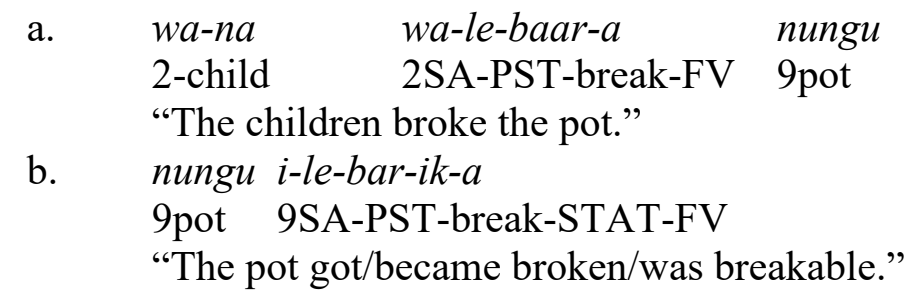

The anticausative alternation illustrated in (2 and 3) has been the subject of much debate in linguistic theory and has raised several intriguing questions. Some of the issues that have been widely discussed in the literature are: (i) the meaning components that determine whether a verb participates in anticausative alternations, (ii) the thematic and syntactic properties of the arguments of (anti-)causatives, (iii) the relationship between anticausative and other transitivity alternations such as passives and middles and (iv) the derivational relationship between the causative and the anticausative variants (see Schäfer 2009; Alexiadou, Anagnostopoulou, and Schäfer 2015). This paper addresses the first three issues using the data from a Bantu language, Kiwoso.

The rest of this paper is organized as follows: Section 2 presents in brief the properties of passive and stative affixes in relation to various semantic verb classes. Properties of change of 
state verbs in anticausative and other related verbal alternations are discussed in Section 3. In this section, the anticausative, passive and middle alternation constructions are examined in combination with various modifications. Section 4 discusses the properties of state verbs in relation to argument realization and anticausative alternation in Kiwoso, whereas Section 5 presents the event decomposition of those verbs. Section 6 presents concluding remarks.

\section{Transitivity alternations in relation to passive and stative suffixes in Kiwoso}

In Bantu languages, passive and stative suffixes are the most productive affixes which can appear with most transitive verbs. Across Bantu languages, passive and stative suffixes change the verbs' grammatical relations (cf. Rugemalira 1995; Mkude 2005). The two forms involve verbal alternations in which their sole argument is the object argument of the transitive sentence, as (4) demonstrates.

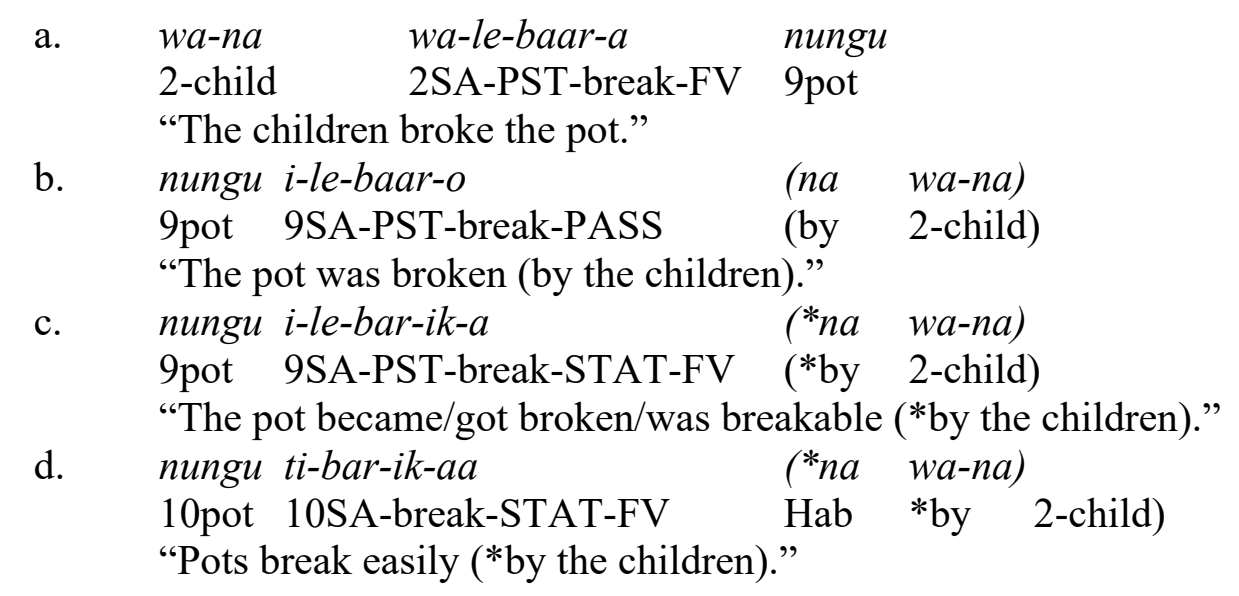

The examples in (4) demonstrate that passive and stative sentences are similar in that their syntactic subject, nungu 'pot' (4.b-d) is the logical object in their respective transitive sentences in (4.a). The examples also indicate that both passive and stative forms are intransitive, involving an internal argument (i.e. a theme) only, which is realized as the grammatical subject. However, whereas the agentive role can be reintroduced in the passives via a na-phrase 'by-phrase', that role is completely removed in statives as the (un)acceptability in (4.c-d) shows. A similar observation has been made for several other Bantu languages such as Kivunjo (Moshi 1998), Chichewa (Dubinsky and Simango 1996; Mchombo 2004), Swahili (Mkude 2005; Seidl and Dimitriadis 2003), Ndebele (Khumalo 2009) and Nyakyusa (Lusekelo 2012).

Scholars postulate that the agent role cannot be reintroduced in stative constructions because statives bind together the patient/theme and agentive roles in one nominal entity (Mchombo 2007; Lusekelo 2012). Mchombo in particular asserts that the DP subject in statives, contrary to that of passives, involves attributes of certain qualities which may be inherent or acquired. $\mathrm{He}$ argues that these attributes characterize the subject of statives as entering a state or condition without an implication of an agent responsible for such a state or condition. Indeed, the change of the state of the subject argument of the stative constructions is conceived as happening on its own without an implication of an external cause. In passives, an entity causing the change of a state or condition is implicitly expressed, as (4.b) demonstrates. 
The data examined indicates that verbs suffixed by the stative do not necessarily express a change of state or a condition of a patient/theme argument across languages. Examples (3.c) and (4.c) demonstrate that in Kiwoso, verbs with stative suffixes have inchoative and potential readings. The inchoative and the potentiality interpretations of the stative suffix are also common to many other Bantu languages as observed for Swahili (Mkude 2005), Kagulu (Petzell 2008), Chichewa (Dubinsky and Simango 1996; Mchombo 2004) and Kinyarwanda (Jerro 2018). The following subsection examines the properties of passive and stative suffixes across semantic verb classes.

\subsection{Passive and stative suffixes across semantic verb classes}

Studies in Bantu languages such as Chichewa (Dubinsky and Simango 1996; Mchombo 2004), Ndebele (Khumalo 2009),Swahili (Seidl and Dimitriadis 2003) and Nyakyusa (Lusekelo 2012), indicate that passive and stative suffixes are productively suffixed to transitive verbs. Mchombo in particular argues that in Chichewa, stative suffixes do not just attach to transitive verbs, but specifically to transitive verbs which are change of state verbs. However, Khumalo (2009) reports that in Ndebele, statives can combine with (intransitive) non-change of state verbs. This discrepancy suggests that the class of alternating verbs is not homogenous across or even within individual languages, as the data examined from Kiwoso also demonstrates (cf. examples 6 and 7).

In Kiwoso, passive and stative suffixes occur mostly with transitive verbs including verbs of change of state (see example 4). However, these suffixes can also co-occur with intransitive verbs, verbs of perception, as well as verbs of psychological state (psych-verbs).Verbs suffixed with the passive morpheme are interpreted as such, but as shown in section (2), verbs with stative suffixes are ambiguously interpreted as inchoative (a simple change of state), potential, and dispositional middle. However, for the verb to acquire dispositional middle reading in Kiwoso, it necessarily combines with the habitual morpheme, and appears in the simple present form, as (5.c) illustrates.
a. ki-elya kya-kor-ik-a
7-food 7SA-cook-STAT-FV
"The food gets/becomes cooked."
b. ki-elya ki-le-kor-ik-a
7-food 7SA-PST-cook-STAT-FV
"The food got/became cooked/was cookable."
c. ki-elya ki-kor-ik-a-a
7-food 7SA-cook-STAT-FV-HAB
"The food cooks easily."

It has been established that in some Bantu languages, passive and stative suffixes are the most productive suffixes and can co-occur with both transitive and intransitive verbs (Lusekelo 2012). In Kiwoso, neither passive nor stative suffixes consistently co-occur with all semantic verb classes. For example, perception verbs such as isya 'feel' cannot occur with passive (6.b) or stative suffixes (6.c). However, there are other members of this category such as faamya 'smell', isya 'hear' that accept passive (7.b) but not stative (7.c). 
(6)

\begin{tabular}{|c|c|c|c|c|}
\hline \multirow[t]{2}{*}{ a. } & $\begin{array}{l}\text { wa-na } \\
\text { 2-child }\end{array}$ & $\begin{array}{l}\text { wa-le-esy- } a \\
\text { 2SA-PST-feel-FV }\end{array}$ & mbyoo & \\
\hline & "Childre & felt cold." & & \\
\hline b. & *mbуоo & $i-l e-s y-o$ & (na & $w a-n a)$ \\
\hline & 9cold & 9SA-PST-feel-PASS & (by & 2-child) \\
\hline c. & *mbyoo & $i-l e-i s-i k-a$ & & \\
\hline
\end{tabular}

(7)
a. wa-na wa-le-faamy-a mafuda
2-child 2SA-PST-smell-FV 10oil
"Children smelled the oil."
b. mafuda a-le-faamy-o (na wa-na)
10oil 10SA-PST-smell-PASS (by 2-child)
"The oil was smelled (by the children)."
c. *mafuda a-le-faam-ik-a
10oil 10SA-PST-smell-STAT-FV

Studies indicate that intransitive motion verbs such as run, arrive, return, sit, walk, dance, go, fall, and come are widely crosslinguistically not supposed to passivize or stativize by virtue of their lexical semantics (see Levin and Rappaport Hovav 1995, Lusekelo 2008). Contrary to this view, verbs like enda 'go', fika 'arrive', dicha 'run/escape', damya 'sit' in Kiwoso accept passive and stative suffixes, as the verb damya 'sit' in (8) exemplifies.
a. $\quad w a-n d u \quad w a-l e-d a m y-a \quad k i-d i$
2-person 2SA-PST-sit-FV 7-chair
"People sat on the chair."
b. ki-di ki-le-damy-o (na wa-ndu)
7-chair 7SA-PST-sit-PASS (by 2-person)
"On the chair was sat (by people)."
c. ki-di ki-le-dam-ik-a
7-chair 7SA-PST-sit-STAT-FV
"The chair was sitable."

However, within the same class, verbs such as wuya 'return' and woo 'fall' do not co-occur with the stative, although they can be passivized, as (9) shows.
a. wa-na wa-le-wuy-a bo
2-child 2SA-PST-return-FV 9home
"Children returned home."
b. bo i-le-wuy-o (na wa-na)
9home 9SA-PST-return-PASS (by 2-child)
"Home was returned by the children."
c. *bo i-le-wuy-uk-a
9home 9SA-PST-return-STAT-FV

The analysis of verb alternations across semantic classes shows that although members of the same class are semantically related,they are not identical in relation to transitivity alternations. 
This observation suggests that semantic verb classes should be organized differently depending on their encyclopaedic characteristics.

The following section examines externally caused verbs in relation to passive, causative, anticausative and middle transitivity alternations, in which passive and stative suffixes form an integral part.

\section{Externally caused change of state verbs: an overview}

Externally caused change of state verbs describe changes in the physical shape or appearance or material integrity of some entity. The majority of these verbs describe eventualities which are brought about by an external cause, namely an agent, an instrument, a natural force, or a circumstance, thus regarded as externally caused change of state verbs (Levin and Rappaport Hovav 1995). Generally, these verbs are characterized as alternating verbs in that they exhibit both transitive (causative) (10.a and 11.a) and intransitive (anticausative) uses (10.b and 11.b), as English and Kiwoso examples illustrate in (10) and (11), respectively. (See also example 1).

(10) a. They broke the window.

b. The window broke.
a. wa-le-many-a mi-ji
2SM-PST-cut-FV 4-tree
"They cut trees."
b. $\quad m i-j i$ ti-le-many-ik-a
4-tree 4SA-PST-cut-STAT-FV
"Trees became cut/were cutable."

In their transitive use, these verbs indicate that the eventualities described are brought about by some external cause, whereas in their intransitive construal the verbs denote the events in which the change of state described come about independently. Distinct from English, anticausative variants in the majority of Bantu languages including Kiwoso are morphologically marked, as example (11) demonstrates. However, the causative and the anticausative alternates are semantically similar in that the subject of the anticausative (intransitive) variant and the object of the causative (transitive) variant are the themes/patients. Evidence suggests that scant research has been done in Bantu languages from these perspectives, although available descriptive grammars and some theoretical studies affirm that these languages have a wealth of insights to offer from both empirical and theoretical viewpoints. This paper aims to examine externally caused change of state verbs in relation to argument alternation properties of (anti-)causative, passive, and middle verb constructions in Kiwoso.

In order to determine the properties of the three verbal argument alternation constructions in argument realization, the analysis of change of state verbs is done in combination with various modifications. In this paper, Levin's (1993) classes of externally caused verbs are maximally utilized. 


\subsection{The externally caused change of state verbs in Kiwoso}

Across languages, externally caused verbs such as break, bend, cook, and cut verbs are characterized as change of state verbs. Intuitively, externally caused change of state verbs are conceived as verbs that describe the events induced or brought about by external causes (Alexiadou, Anagnostopoulou and Schäfer2006, 2015; Schäfer 2009). These verbs are characterized as actions that bring about a change in the physical shape or appearance of some entity through an external cause. Kiwoso externally caused verbs such as break verbs (viz. baara 'break', saka 'grind', aswo 'crack', and ratwo 'tear'), bend verbs (viz. lema 'fold', pinda 'wrinkle', and lema 'bend'), cook verbs (viz. kora 'cook', sambuta 'warm', warata 'heat', and chemsha 'boil'), as well as cut verbs (viz. manya 'cut', racha 'slash', randa 'saw' and dummbo 'slice') are examined in terms of their (anti-)causative, passive and middle alternation properties.

Because it is impossible to present examples of all class members, one prototypical member is selected from each class as a representative sample. In order to characterize argument realization patterns, different diagnostics are employed. However, members of the same class may behave differently when they co-occur with certain modifications. If this happens, the variation will be pointed out and discussed accordingly.

\subsubsection{The causative variants of externally caused verbs in Kiwoso}

It has been noted that the external argument position of change of state verbs can be realized by different types of subject arguments (Levin and Rappaport Hovav 1995; Alexiadou and Schäfer 2006). In the analysis of causative forms of the externally caused verbs in Kiwoso, different external arguments such as an agent, an instrument and a natural force (causer) have been examined in the causative sentences. In order to validate the suitability of these external arguments in subject position, standard subject tests have been used in combination with other modifications, as shown in the subsections that follow.

\subsubsection{Agent/Instrument as subject argument}

All externally caused verbs examined in Kiwoso demonstrate that an agent or an instrument can be a subject argument of the causative variants, and that the same arguments can be realized in passive variants, as shown in (12.a) and (12.b), respectively.
a. wa-na/i-wee
wa/lyi-le-baar-a
nungu
2-child/5-stone
2/5SA-PST-break-FV
9pot
"Children/the stone broke the pot."
b. nungu i-le-baar-o (na
$w a-n a) /(n a$
$i$-wee)
9pot 9SA-PST-break-PASS (by 2-child)/ (by 5-stone)
"The pot was broken (by the children)/ (with (by means of) the stone)."

The noun wana 'children' in (12) denotes an agent of the event described by the verb, while iwee 'stone' denotes an instrument. Such an agent and an instrument are perceived as the cause of the change of state undergone by the theme, i.e. the breaking of the pot. Generally, all externally caused verbs in Kiwoso show that an agent or an instrument is an acceptable subject argument in causative verb constructions. 


\subsubsection{Natural force as subject argument}

Unlike the agent and instrument arguments, within and across semantic verb classes of externally caused verbs there are variations with regard to noun phrases denoting natural force as an external argument. On the one hand, all members of cook and cut verbs in Kiwoso cannot co-occur with a natural force, as illustrated by the verb manya 'cut' in (13.a). On the other hand, the sentences examined indicate that while all other members of the break verbs accept natural force as an external argument (3.b-c), the verb saka 'grind' is incompatible with natural force as its subject, as the semantic anomaly of example (13.d) indicates.

\begin{tabular}{|c|c|c|c|}
\hline a. & $\begin{array}{l}\text { \#иреро } \\
\text { 11wind }\end{array}$ & $\begin{array}{l}\text { lu-le-many- } a \\
\text { 11SA-PST-cut-FV }\end{array}$ & $\begin{array}{l}n \text {-ji } \\
\text { 4-tree }\end{array}$ \\
\hline & "The wil & the tree." & \\
\hline b. & $\begin{array}{l}\text { upepo } \\
11 \text { wind } \\
\text { "The wil }\end{array}$ & $\begin{array}{l}\text { lu-le-baar-a } \\
\text { 11SA-PST-break-FV } \\
\text { ke the pot." }\end{array}$ & $\begin{array}{l}\text { nungu } \\
\text { 9pot }\end{array}$ \\
\hline c. & $\begin{array}{l}\text { upepo } \\
11 \text { wind } \\
\text { "The wil }\end{array}$ & $\begin{array}{l}\text { lu-le-ratu-o } \\
\text { 11SA-PST-tear-FV } \\
\text { e the cloth." }\end{array}$ & $\begin{array}{l}\text { ki-tambaa } \\
\text { 7-cloth }\end{array}$ \\
\hline d. & $\begin{array}{l}\text { \#upepo } \\
\text { 11wind } \\
\text { "The wil }\end{array}$ & $\begin{array}{l}\text { lu-le-sak-a } \\
\text { 11SA-PST-grind-FV } \\
\text { und the millet." }\end{array}$ & $\begin{array}{l}\text { umbi } \\
\text { 9millet }\end{array}$ \\
\hline
\end{tabular}

The examined sentences in Kiwoso demonstrate that cook and cut verbs as well as the verb saka 'grind' are similar in that these verbs describe eventualities which are necessarily brought about by volitional human agent arguments. Thus, these verbs cannot license nonvolitional arguments such as causers, as evidenced in (13.a) and (13.d).

However, while the verbs of cooking and cutting do not allow a natural force as an external argument in any context, examples of bend verbs demonstrate that members of this category can license natural force as an external causer of events, but this is subject to object selectional restrictions. For example, the verb lema 'fold' behaves differently, as examples in (14) illustrate.
a.
upepo
lu-le-lem- $a$
i-bati
11 wind
11SA-PST-fold-FV
5-iron sheet
"The wind folded an iron-sheet."
b. \#upepo lu-le-lem-a chuma
11wind 11SA-PST-bend-FV 9iron bar
"The wind bent the iron bar."

The examples in (14) illustrate that a natural force upepo 'wind' in (14.a) with the object argument ibati 'iron sheet' is acceptable, but the same modifier is odd in (14.b) due to the type of object argument. Logically, wind is generally construed as incapable of inducing a change to something as hard as an iron bar. 


\subsubsection{Agent-oriented phrase modification}

The example sentences examined in Kiwoso demonstrate that all causative and passive variants of externally caused verbs accept agent-oriented adverbs such as ko ngufu 'forcefully', as (15) illustrates.

$$
\begin{aligned}
& \text { a. wa-ka wa-le-baar-a nungu (ko ngufu) } \\
& \text { 2-woman 2SA-PST-break-FV 9pot (with force) } \\
& \text { "Women broke the pot (forcefully)." } \\
& \text { b. nungu i-le-baar-o (kitondo) } \\
& \text { 9pot 9SA-PST-break-PASS (with foolish) } \\
& \text { "The pot was broken (foolishly)." }
\end{aligned}
$$

\subsubsection{Purpose clause modification}

Purpose clause modification is also used as a diagnostic test for agentivity. Externally caused verbs analyzed in Kiwoso indicate that a purpose clause suitably modifies both the causative and the passive sentences, as (16) shows.
a. wa-ka wa-le-baar-a
nungu (kusudi wa-la-kor-e)
2-woman 2SA-PST-break-FV 9pot (so that 2SA-NEG-cook-FV)
"Women broke the pot (so that they do not cook)."
b. nungu i-le-baar-o (kusudi i-la-kor-e)
9pot 9SA-PST-break-PASS (so that 9SA-NEG-cook-FV)
"The pot was broken (so that it is not used for cooking)."

\subsubsection{Manner/Instrument adjunct modifications}

The causative and passive variants of the externally caused change of state verbs examined in Kiwoso indicate that all members can co-occur with manner as well as instrument adjuncts, as evidenced in (17).
a. $w a-k a$
wa-le-baar-a nungu
(bhicho)/(na i-wee)
2-woman
2SA-PST-break-FV 9pot
(bad)/ (by 5-stone)
"Women broke the pot (badly)/ (with a stone)/ (by means of a stone)."
b. nungu i-le-baar-o
9SA-PST-break-PASS
(bhicho)/(nai-wee)
9 pot
(bad)/ (by 5 -stone)
"The pot was broken (badly)/ (by (the use of) a stone)."
c. wa-ka wa-le-me-baar-a nungu (*bhicho)
2-woman 2SA-PST-PERF-break-FV 9pot (*bad)
"Women had broken the pot (*badly)."

Notice that the manner adjunct bhicho 'badly' and the instrument adjunct na iwee 'by a stone' provide information on 'how' an agent performs the event. It has also been observed that the co-occurrence of manner adjuncts with change of state verbs in Kiwoso is determined by the grammatical aspect of a sentence. A manner adjunct cannot co-occur in a sentence with a perfective or result state interpretation, as example (17.c) shows. A causative verb in its simple past as in (17.a) denotes a process event and hence it accepts manner adjuncts, whereas 
the verb in a perfect tense denotes an event with logical culmination which is interpreted as a result state, thus incompatible with manner adjunct modification. Similar results are obtained in passive verb constructions.

\subsubsection{Temporal phrase modification}

Externally caused verbs examined in Kiwoso demonstrate different characteristics in terms of aspectual classes (event semantics). Example sentences examined indicate that in its simple verb constellation, break verbs denote Achievement events, whereas cut, cook and bend verbs denote Activity events. Additionally, whereas cut, cook and bend verbs co-occur with both time-frame and durative adverbial modifications (18.a),break verbs are incompatible with durative adverbials such as ko sekunde 'for a second' because they indicate instantaneous events and, therefore, do not co-occur with (atelic) durative adverbials, as (18.b) shows.
a.
Leka ni-a-le-many-a
$n-j i$
(ko isaa)/(isaa)
Leka INIT-SA-PST-cut-FV 3-tree (for hour)/(hour)
"Leka cut the tree (for an hour)/ (in an hour)."
b. wa-ka wa-le-baar-a nungu (*ko sekunde)/ (sekunde)
2-woman 2SA-PST-break-FV 9pot (for second)/ (second)
"Women broke the pot (*for a second)/ (in a second)."

Externally caused verbs examined in Kiwoso indicate that the grammatical aspect in Kiwoso determines the aspectual interpretations of externally caused verb constructions. It has been realized that when these verbs co-occur with a perfective morpheme, as in (19), they denote logical termination of the events, hence they receive result state interpretations which are incompatible with temporal adverbials, as evidenced in (19).
Leka a-le-me-many-a
$n-j i$
$(* k o$ isaa $) / \quad(* i s a a)$
Leka SA-PST-PERF-cut-FV 3-tree (*for hour)/ (*hour)
"Leka had (already) cut the tree (*for an hour)/ (*in an hour)."

Section 3.1.1 characterized externally caused verbs in causative and passive verb constructions. These constructions are examined in combination with various modifications in order to establish their properties in external argument realization, and the aspectual properties associated with the causatives (transitives) and their passive counterparts in Kiwoso. The sentences examined demonstrate that externally caused verbs in Kiwoso realize different types of external arguments, namely an agent, an instrument and a causer. However, whereas causative verb constructions realize the external arguments explicitly, the same are introduced by a $n a$-phrase ' $b y$-phrase' in passive variants. The data further establishes that these verbs do not behave similarly in terms of aspectual properties, as the examples in (18) demonstrate. The following section shifts attention to anticausative constructions.

\subsubsection{The anticausative alternations of externally caused verbs in Kiwoso}

It has been mentioned in section (3) that change of state verbs have transitive (causative) and (intransitive) anticausative uses. Externally caused verbs in Kiwoso are prototypical change of state verbs which widely alternate. In this language, the anticausative alternates of externally caused verbs are characterized by the stative suffix - $\boldsymbol{i k}$ - (and its related forms). The stative 
suffix can be regarded as an element that prohibits the assignment of external theta roles in anticausative sentences (see also section 2.1). The data from Kiwoso indicates that the causative and anticausative variants differ in terms of argument realization, as the diagnostics presented in the following subsections evidence.

\subsubsection{Agent/Instrument/Natural force as subject}

The anticausative variants of externally caused verbs examined in Kiwoso demonstrate that contrary to causative variants, anticausatives cannot co-occur with an agent, an instrument, or a causer as external arguments. However, the verb saka 'grind' and cook verbs are unique in that the instrument can function as a subject argument of these verbs, as the verb kora 'cook' in (20) exemplifies.

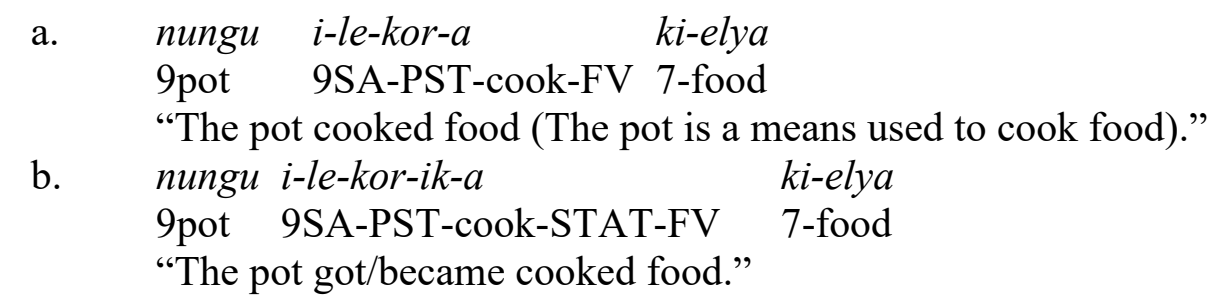

The instrument nungu 'pot' in (20.a) is interpreted as the potential or possible tool used in carrying out the cooking event. On the one hand, the instrument in (20.a) modifies the participant rather than the event described by the verb. On the other hand, in (20.b), the event described by the verb is stated to be possible by means of such an instrument, and the instrument modifies the entire event rather than the participant (argument).

\subsubsection{Prepositional phrase modification}

It has been established that across languages, anticausative variants license specific prepositions introducing causer arguments (cf. Alexiadou, Anagnostopoulou and Schäfer 2006, 2015; Kalluli 2007; Schäfer 2008). The externally caused verbs examined in this paper indicate that the distribution of prepositional phrases related to the realization of the external argument differs depending on how the arguments are construed. In causative and passive verb constructions, the external arguments are perceived as entities, both volitional and nonvolitional, capable of carrying out the action. The anticausative variants examined here do not license external arguments, but they do license event modifiers which are basically introduced by a ko-phrase. Event modifiers indicate the suitability, possibility, ability, or potentiality of the event occurrence. However, while all other identified verbs are compatible with all the modifiers, as in (21), natural force modification is unacceptable with the verb saka 'grind' (22), and with all cut, cook and bend verbs, as the verb cut in (23) exemplifies.

$$
\begin{aligned}
& \text { nungu i-le-bar-ik-a (ko wa-ka)/ (ko i-wee)/ (ko upepo) } \\
& \text { 9pot 9SA-PST-break-STAT-FV (to 2-woman)/(by 5stone)/ (from 5wind) } \\
& \text { "The pot became broken (through women)/(through stone)/(from wind)." }
\end{aligned}
$$

$$
\begin{aligned}
& \text { umbi u-le-sak-ik-a (ko wa-ka)/ (ko isebhe)/ (*ko upepo) } \\
& \text { 9millet 9SA-PST-grind-stat-FV (to 2-woman)/(by 5grindingstone)/(*by 5wind) }
\end{aligned}
$$


"Millet became ground (to the ability of the women) $/($ through grinding stone $) /(*$ from wind)."
$n$-ji u-le-many-ik-a

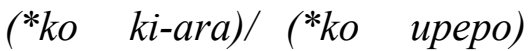
3-tree 3SA-PST-cut-STAT-FV (with 7-axe)/ (by 11wind)
"The tree became cut/was cutable (*by axe) (by means of an axe)/(*by wind)."

\subsubsection{Agentive modifications}

The data examined indicates that the anticausative variants of these verbs do not allow agentive modifiers such as agent-oriented adverbs and purpose clauses, as exemplified in (24). This is due to the fact that anticausative sentences in Kiwoso lack agentive inferences and, therefore, modifiers of this nature cannot be accessed, as evidenced in (24).
a. nungu i-le-bar-ik-a
(*ko makusudi)
9pot 9SA-PST-break-STAT-FV (with purpose)
"The pot became broken (*intentionally)."
b. nungu i-le-bar-ik-a
(*kusudiilatumike)
9pot 9SA-PST-break-STAT-FV (*so that it is not used)
"The pot became/got broken (*so that it is not used)."

\subsubsection{Manner/Instrument adjuncts modifications}

As for the causative and passive variants of externally caused verbs discussed in the previous section, anticausative variants are felicitous with both manner and instrument adjuncts, as exemplified by kora'cook' in (25).

$$
\begin{array}{llll}
\text { ki-elya } & \text { ki-le-kor-ik-a } & \text { (uwin)/ } & \text { (ko nungu) } \\
\text { 7-food } & \text { 7SA-PST-cook-STAT-FV } & \text { (quickly)/ (with 9pot) } \\
\text { "The food became cooked/(quickly)/(by means of a pot)." }
\end{array}
$$

Notice that in causative variants, manner and instrument adjuncts modify an event participant, (i.e. an argument) but in anticausatives, the instrument and manner adjuncts modify the entire event.

\subsubsection{Temporal adjuncts modifications}

Basically, the anticausative variants of externally caused verbs in Kiwoso denote a state event in terms of aspectual properties. The sentences examined demonstrate that all verbs are compatible with a time-frame adverbial such as sekunde 'second', and that such a combination alters the aspectual classes of the verbs from State to Accomplishment, as exemplified by the verb manya 'cut' in (26).

$$
\begin{array}{llcl}
n-j i & u \text {-le-many-ik- } a & \text { (masaaadadu)/ } & \text { (ko masaaadadu) } \\
\text { 3-tree } & \text { 3SA-PST-cut-STAT- FV } & \text { (hours three)/ } & \text { (for hours three) } \\
\text { "The tree became cut/was cutable (in three hours)/(for three hours)." }
\end{array}
$$


Anticausative constructions examined in combination with durative adverbials indicate that externally caused verbs are distinct in this aspect. The data establishes that cut and cook verbs can co-occur with durative adverbials such as ko masaaadadu 'for three hours', as shown in (26), but not for break and bend verbs, as (27) illustrates.

$$
\begin{aligned}
& \text { nungu } i \text {-le-bar-ik-a } \quad \text { (*ko sekunde) } \\
& \text { 9pot 9SA-PST-break-STAT-FV (*for } \text { second) } \\
& \text { "The pot got/became broken (*for a second)." }
\end{aligned}
$$

Section 3.1.2 examined the properties of anticausative verb constructions of externally caused verbs in relation to argument realization and event semantics. The results indicate that all verbs participate in the anticausative alternation. It has been established that anticausative variants of externally caused verbs behave differently in terms of external argument realization. The anticausative verb construction in Kiwoso does not license external arguments, it realizes event modifiers which are exclusively introduced by a $k o$-phrase. The following section focuses on middle verb constructions.

\subsubsection{Middle verb constructions in Kiwoso}

Across languages, the morphosyntax of the middle construction is similar and closely relates to passive and anticausative constructions in terms of argument alternation properties (see Schäfer 2008, 2009; Dom and Bostoen 2018; Jerro 2018). For these constructions, the verb's underlying internal argument surfaces as the grammatical subject. Middle constructions are characterized by their generic meaning. In middle construction, the theme argument denotes a particular property in general, as $u b a n u$ 'eucalyptus' in example (28.b) indicates.

Scholars have reported that one of the strategies of marking the middle in many Bantu languages is the use of the stative morpheme - $i k$ - (see Seidl and Dimitriadis 2003; Fernando 2013; Dom, Kulikov and Bostoen 2016; Jerro 2018). These scholars add that apart from marking middles, the morpheme has different readings including the anticausative and stative. Schäfer (2008) observes that if a certain language involves some morphological device to mark anticausatives, it is the same device used to form middles in that language. This observation is borne out in Kiwoso in that similarly to anticausatives, middle constructions of all externally caused verbs are marked by the morpheme $-i k$-. However, unlike anticausatives, middle sentences obligatorily involve the habitual morpheme $-a$ - which denotes the generic

\begin{tabular}{|c|c|c|c|}
\hline $\mathrm{a}$ & $\begin{array}{l}\text { wa-ndu } \\
\text { 2-people }\end{array}$ & $\begin{array}{l}\text { wa-le-many-a-ubanu } \\
\text { 2SA-PST-cut-FV-11 eucalyptus }\end{array}$ & $\begin{array}{l}\text { (uwin) } \\
\text { (quickly) }\end{array}$ \\
\hline & "People cut the & e eucalyptus (tree) quickly.” & \\
\hline b. & $\begin{array}{l}\text { ubanu } \\
\text { 11Eucalyptus }\end{array}$ & $\begin{array}{l}\text { lu-many-ik- } a-a \\
\text { 11SA-cut-STAT-FV-HAB }\end{array}$ & $\begin{array}{l}\text { (uwin) } \\
\text { (quickly) }\end{array}$ \\
\hline
\end{tabular}
meaning of middle, as (28) illustrates.

The sentences examined in Kiwoso indicate that in middle constructions, a quality denoted by the verb is attributed to the grammatical subject (the theme). Thus, example (28) indicates that it is the property of the grammatical subject ubanu 'eucalyptus' which makes the event of cutting it possible, or potential. The results of the data examined demonstrate further that 
unlike anticausatives, middle sentences lack specific time reference, thus they are incompatible with the past tense, as (29) shows.

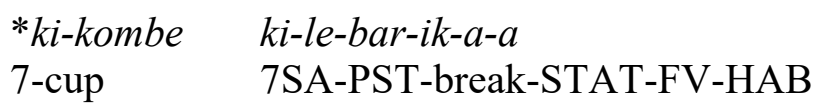

In order to establish external argument realization patterns, middle sentences are also examined in combination with various diagnostics such as agentive modifiers, purpose clauses and preposition phrase modifications. The data indicates that similarly to anticausatives, agentive adverbials and purpose phrases, as exemplified in (30) are unacceptable in middle constructions. However, other modifiers introduced by a ko-phrase, as in (31) are acceptable.

$\begin{array}{llll}\text { shuka } & \text { ti-lem-ik-a-a } & \text { nicha } & \text { (*kirango) } \\ \text { 10bedsheets } & \text { 10SA-fold-STAT-FV-HAB } & \text { nice } & \text { (clever) } \\ \text { "Bedsheets fold nicely (*cleverly)." } & & \end{array}$

$$
\begin{aligned}
& \text { nungu i-bar-ik-a-a (ko womi)/(*na womi) } \\
& \text { 9pot 9SA-break-STAT-FV-HAB (to men)/ (*by men) } \\
& \text { "The pot breaks (easily) (to the ability/potentiality of men)/(*by men)." }
\end{aligned}
$$

The (non-) co-occurrence of an agent-oriented adverb in (30) implies that middles do not involve the type of implicit external argument found with passives (see example 15.b). Conversely, example (31) demonstrates that middles can realize other modifiers introduced by a ko-phrase, but they are illicit with a na-phrase, which carries agentive features.

In summary, the data examined in this section demonstrates that externally caused change of state verbs can appear in causative, passive, anticausative, and dispositional middle constructions. The results illustrate that externally caused verbs realize different types of external arguments, namely agents, instruments, and natural forces as external arguments in causative and passive variants, with slight variations. On the one hand, passives can license arguments with agentive features via a na-phrase 'by-phrase'. On the other hand, anticausative and middle verb constructions realize event modifiers which are entirely introduced by ako-phrase. The summary of the diagnostics used with externally caused verbs are presented in Table 1 . Section 4 characterizes the properties of externally caused change of state verbs in relation to argument realization properties of (anti-)causative, passive and middle verb alternation constructions. 


\begin{tabular}{|c|c|c|c|c|c|c|c|c|c|c|c|c|c|c|c|c|c|c|c|c|c|c|c|c|c|c|c|c|c|c|c|c|c|}
\hline \multirow{4}{*}{ 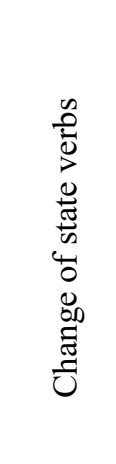 } & \multicolumn{9}{|c|}{ CAUSATIVE } & \multicolumn{10}{|c|}{ PASSIVE } & \multicolumn{10}{|c|}{ ANTICAUSATIVE } & \multicolumn{4}{|c|}{ MIDDLE } \\
\hline & \multicolumn{9}{|c|}{ DIAGNOSTICS } & \multicolumn{10}{|c|}{ DIAGNOSTICS } & \multicolumn{10}{|c|}{ DIAGNOSTICS } & \multicolumn{4}{|c|}{ DIAGNOSTICS } \\
\hline & \multirow[b]{2}{*}{ 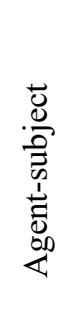 } & \multirow[b]{2}{*}{ 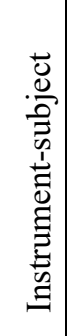 } & \multirow[b]{2}{*}{ 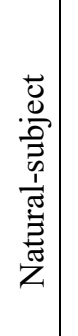 } & \multirow[b]{2}{*}{ 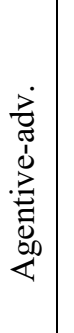 } & \multirow[b]{2}{*}{$\begin{array}{l}0 \\
0 \\
0 \\
\vdots \\
\vdots \\
\vdots \\
0\end{array}$} & \multicolumn{2}{|c|}{$\begin{array}{l}\text { Tem. } \\
\text { adv }\end{array}$} & \multirow[b]{2}{*}{ 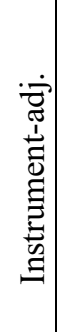 } & \multirow[b]{2}{*}{ 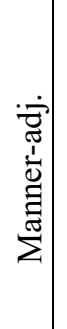 } & \multirow[b]{2}{*}{ 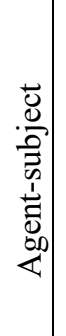 } & \multirow[b]{2}{*}{ 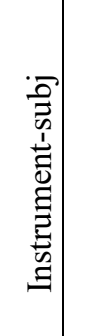 } & \multirow[b]{2}{*}{ 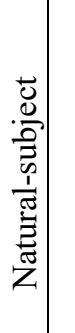 } & \multirow[b]{2}{*}{ 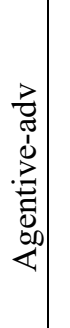 } & \multirow[b]{2}{*}{ 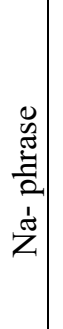 } & \multirow[b]{2}{*}{$\begin{array}{l}0 \\
0 \\
0 \\
\vdots \\
\vdots \\
0\end{array}$} & \multicolumn{2}{|c|}{$\begin{array}{l}\text { Tem. } \\
\text { adv }\end{array}$} & \multirow[b]{2}{*}{ 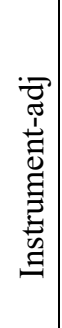 } & \multirow[b]{2}{*}{ 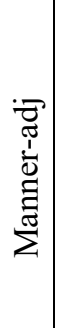 } & \multirow[b]{2}{*}{ 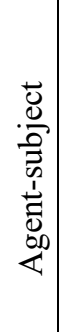 } & \multirow[b]{2}{*}{ 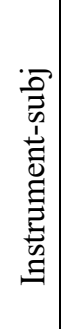 } & & & & & $\begin{array}{l}\mathrm{Te} \\
\mathrm{ac}\end{array}$ & & & & & & $\mathrm{PI}$ & \\
\hline & & & & & & రั) & $\Xi$ & & & & & & & & & 容 & $\Xi$ & & & & & 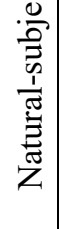 & 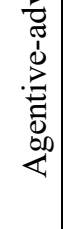 & $\begin{array}{l}\tilde{D} \\
\tilde{\Xi} \\
\vec{\Xi} \\
\vec{a} \\
\dot{0} \\
v\end{array}$ & $\begin{array}{l}0 \\
0 \\
0 \\
0 \\
\vdots \\
\vdots \\
2\end{array}$ & పั & $\Xi$ & 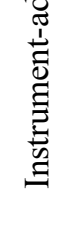 & 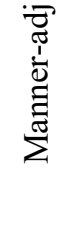 & 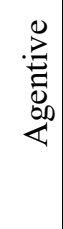 & $\begin{array}{l}0 \\
\ddot{0} \\
0 \\
\vdots \\
\vdots\end{array}$ & $\stackrel{0}{1}$ & $\ddot{z}$ \\
\hline $\begin{array}{l}\text { baara' } \\
\text { break' }\end{array}$ & $\checkmark$ & $\checkmark$ & $\checkmark$ & $\checkmark$ & $\checkmark$ & * & $\checkmark$ & $\checkmark$ & $\checkmark$ & $\checkmark$ & $\checkmark$ & $\checkmark$ & $\checkmark$ & $\checkmark$ & $\checkmark$ & * & $\checkmark$ & $\checkmark$ & $\checkmark$ & * & $\checkmark$ & * & * & $\checkmark$ & * & * & $\checkmark$ & $\checkmark$ & $\checkmark$ & * & $*$ & $\checkmark$ & $*$ \\
\hline $\begin{array}{l}\text { manya } \\
\text { 'cut' }\end{array}$ & $\checkmark$ & $\checkmark$ & $\#$ & $\checkmark$ & $\checkmark$ & $\checkmark$ & $\checkmark$ & $\checkmark$ & $\checkmark$ & $\checkmark$ & $\checkmark$ & * & $\checkmark$ & $\checkmark$ & $\checkmark$ & $\checkmark$ & $\checkmark$ & $\checkmark$ & $\checkmark$ & $*$ & $*$ & * & * & $\checkmark$ & $*$ & * & $\checkmark$ & $\checkmark$ & $\checkmark$ & $*$ & * & $\checkmark$ & * \\
\hline $\begin{array}{l}\text { kora } \\
\text { 'cook' }\end{array}$ & $\checkmark$ & $\checkmark$ & $\checkmark$ & $\checkmark$ & $\checkmark$ & * & $\checkmark$ & $\checkmark$ & $\checkmark$ & $\checkmark$ & $\checkmark$ & $\checkmark$ & $\checkmark$ & $\checkmark$ & $\checkmark$ & * & $\checkmark$ & $\checkmark$ & $\checkmark$ & * & * & $*$ & * & $\checkmark$ & * & * & $\checkmark$ & $\checkmark$ & $\checkmark$ & $*$ & * & $\checkmark$ & * \\
\hline $\begin{array}{l}\text { lema } \\
\text { 'fold' }\end{array}$ & $\checkmark$ & $\checkmark$ & $\checkmark$ & $\checkmark$ & $\checkmark$ & * & $\checkmark$ & $\checkmark$ & $\checkmark$ & $\checkmark$ & $\checkmark$ & $\checkmark$ & $\checkmark$ & $\checkmark$ & $\checkmark$ & * & $\checkmark$ & $\checkmark$ & $\checkmark$ & * & * & * & * & $\checkmark$ & * & * & $\checkmark$ & $\checkmark$ & $\checkmark$ & * & * & $\checkmark$ & * \\
\hline
\end{tabular}

Table 1: Externally caused change of state verbs with various modifiers in Kiwoso 


\section{Characteristics of change of state verbs in relation to argument realization and (anti-)causative alternations in Kiwoso}

This paper employs the syntactic decomposition approach as proposed by Alexiadou, Anagnostopoulou, and Schäfer $(2006,2015)$ and Alexiadou (2010) in order to account for the (anti-)causative properties of state verbs in Kiwoso. The approach is built on the key assumption of the Distributed Morphology Framework which states that roots combine with different flavours of $v$ and Voice, which may influence the encyclopaedic information associated with a root. Following that idea, the (anti-)causative alternations of the externally caused verbs in Kiwoso can be explained in terms of the properties of the Root in combination with a Voice and a vCAUS functional head. The data examined indicates that causative and anticausative variants of externally caused verbs in Kiwoso involve the same root but differ in terms of functional heads.

There is a standard assumption in the literature that verbs of change of state, particularly the externally caused verbs, participate in causative and anticausative alternations (Levin and Rappaport Hovav 1995; Schäfer 2008, 2009). This assumption is borne out for Kiwoso because all externally caused verbs examined alternate (see sections 3.1.1 and 3.1.2). The findings of the data examined indicates that contrary to the widely held view in the literature that agentive verbs do not alternate (see Levin and Rappaport Hovav 1995; Alexiadou, Anagnostopoulou, and Schäfer 2006, 2015; Schäfer 2009) in Kiwoso, verbs such as manya 'cut' and kora 'cook', do alternate (see examples 20, 23, 25, 26).

The findings demonstrate that all externally caused verbs, including agentive verbs which are regarded as non-alternating in other languages (cf. Levin and Rappaport Hovav 1995; Alexiadou, Anagnostopoulou and Schäfer 2006, 2015; Schäfer 2008, 2009) exhibit (anti)causative alternations in Kiwoso, as evidenced in cut and cook verb constructions. This observation suggests that the selectional properties of roots in terms of whether they combine with vCAUS or Voice functional heads may be language-specific, and thus similar verbs describing similar events may be conceived differently depending on which functional head they combine with.

The semantic classes of cut and cook verbs in Kiwoso denote eventualities that are conceptualized as human-oriented, thus the changes of state expressed by these verbs require the participation of an intentional human agent to bring about the change described by the verbs. It has also been noted that although verbs generally alternate, they are not homogenous. The findings establish that members of semantic verb classes in Kiwoso are not identical in terms of alternation properties. Within a single class, there are members that alternate, and there are others that do not (see examples 6, 7, and 9 in section 2.1). This suggests that the encyclopaedic lexical semantic properties of the individual root, and how it combines with functional heads, determine its possibilities for alternations.

\section{Event decomposition of change of state verbs in Kiwoso}

The constructions examined in Kiwoso indicate that unlike causative alternates, all anticausative variants of externally caused verbs are morphologically marked by the stative morpheme -ik-. The variations that exist between these verbs prompted the adoption of a 
syntactic decomposition approach that takes causative and anticausative as sharing a common Root in that neither variant is derived from the other by either lexical rules or any syntactic transformation.

The approach assumes that causative and anticausative verbs are all based on a Root and a Theme that bears a resultant state, and a CAUS component which takes the resultant state as its complement (Alexiadou, Anagnostopoulou, and Schäfer 2006). The CAUS represents a causal relation between a causing event and the resultant state. Based on this view, there is no directionality relationship between the causative and the anticausative alternations, thus the two variants result from the same verb root. For example, the causative alternate in (32) has a Voice and a vCAUS functional head. The Voice node denotes the presence of external argument womi 'men' whereas the vCAUS represents the bringing about of a causal relation between a causing event and the resultant state (i.e. the new state of a tree) denoted by the verb manya 'cut'.

The proposals assumed in the syntactic decomposition approach adequately account for the event decomposition of the data examined in this paper. According to this approach, all causative sentences of the externally caused verb examined in section 3.1.1, as exemplified in (32.a), decompose as (32.b), yielding an abstract structure in (33).

$\begin{array}{lll}\text { a. } & \text { womi wa-le-many-a } & n \text {-ji } \\ & \text { 2man 2AGRs-PST-cut-FV } & \text { 3-tree } \\ \text { "Men cut the tree." } & \\ \text { b. } & \text { [womi [Voice [vCAUS [manya nji]]] }\end{array}$

[Voice (external argument (EA) +agentive (+AG)) [vCAUS [ $\sqrt{ }$ Root]]]

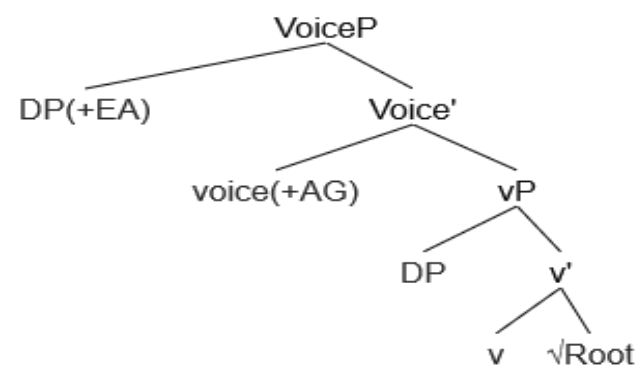

Figure 1: Event decomposition of causative variant of cut verbs

In Figure 1, the DP in Spec, VoiceP denotes the agent argument (external argument). The Voice head establishes a relation between the agent argument (with agentive feature) and the event. The Voice head is the one which bears the semantic feature related to agentivity [+AG] (see Alexiadou 2010). In Kiwoso, cut and cook verbs, as well as the verb saka 'grind' are semantically agentive, thus requiring agentive (AG) external arguments, as figure (1) illustrates. Basically, external arguments of these verbs are necessarily human agents, and hence characterized as involving agentive Voice (Voice $[+A G]$ ).

According to the syntactic decomposition approach, Voice head introduces two thematic notions, namely an agent and a causer. The two notions result into two different Voice 
relations, i.e $\mathrm{R}$ (agent) (see the structure in 33) and $\mathrm{R}$ (caus) (34.b). In Kiwoso, the decomposition of causative variants of $c u t$ and cook verbs involve R(agent). The anticausative verbs do not license agents, instruments, or causers as external arguments realized in causative verbs. However, agents, instruments and causers manifest as event modifiers in anticausatives if they are introduced by a ko-phrase in $\mathrm{vP}$, licensing the vCaus component, which yields the R(caus), as evidenced in (34).

a. $\quad n$-ji u-le-many-ik-a

3-tree 3SA-PST-cut-STAT-FV

"The tree became cut/was cutable."

b. [vCaus [manyika]]

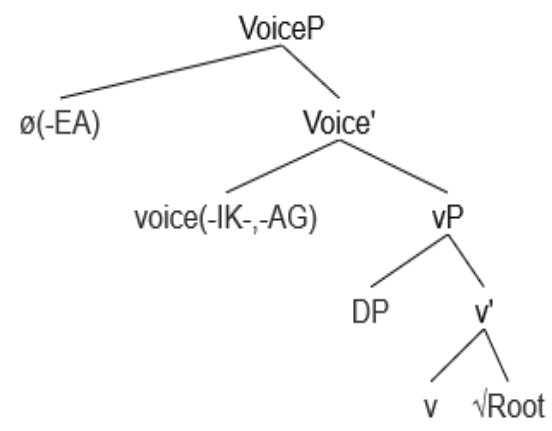

Figure 2: Event decomposition of anticausatives in Kiwoso

It has been pointed out that the anticausative variant in Kiwoso is marked by the -ikmorpheme. This suffix is regarded as the Voice features that alter the anticausative sentences to DP V-intransitive. The suffix - $i k$ - is also the morphological instantiation of the absence of the external argument. The semantic feature of the voice node in anticausative constructions lacks agentivity (Voice [-AG]), as Figure 2 illustrates. The DP in Spec., vP in the Figure is the Theme argument. (See also Figures 1, 3 and 4).

The discussion on passive verb examined in Kiwoso demonstrates that similarly to anticausatives, passive sentences lack external arguments. However, unlike anticausatives, passives licence implicit external arguments including agents, instruments and causers. The results demonstrate that passive forms of cut and cook verbs, as well as the verb saka 'grind' do not license causers. It has been shown in Figure 1 that a Voice head in causative sentences realizes an external argument in its specifier position. In passives, the argument with the relevant thematic role is implicit, as Figure 3 demonstrates.

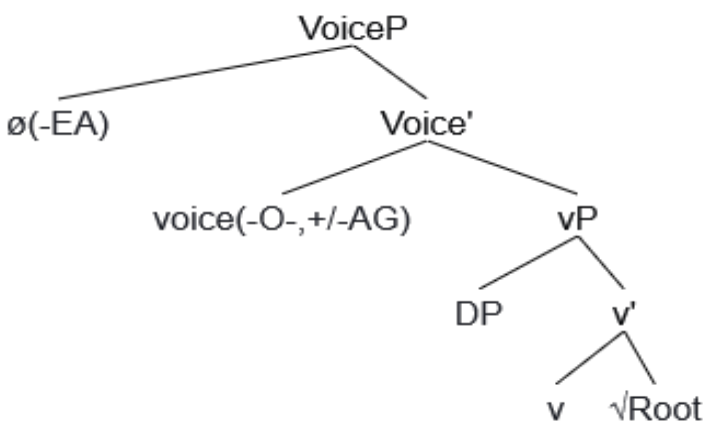

Figure 3: Event decomposition of passives in Kiwoso 
In Figure 3, the morpheme - $o$ - is the morphological realization of passive voice. It has been shown that passive forms can realize both agentive and non-agentive arguments. Hence, passives have the feature (Voice [+/-AG]). The implicit agent and instrument arguments are characterized as (Voice $[+A G]$ ), while the implicit causer argument has the feature (Voice [$\mathrm{AG}])$.

The data illustrates that anticausative, passive and middle verb alternation constructions share the feature that their external argument cannot be expressed. The examined data in Kiwoso demonstrates that while external arguments in passives can be reintroduced via a $n a$-phrase 'by-phrase', this is not the case for anticausative and middle sentences, as shown in (35).
a. wa-na wa-le-baar-a nungu
2-child 2SA-PST-break-FV 9pot
"Children broke the pot."

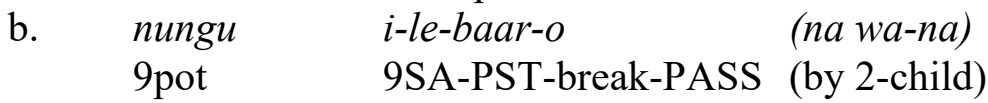
"The pot was broken (by the children)."
c. nungu i-le-bar-ik-a
9pot 9SA-PST-break-STAT-FV
"The pot became/got broken/was breakable."
d. nungu ti-bar-ik-a-a
10pot 10SA-break-STAT-FV-HAB
"Pots break (easily)."

Although the three constructions illustrated by (35.b-d) share some of syntactic properties, the data examined show that middle sentences are distinct from anticausative and passive verb constructions in the sense of being generic statements, which lack specific time references. Thus, the sentences with a dispositional middle interpretation are ungrammatical with a past tense, as evidenced in (36).

$$
\begin{array}{lll}
\text { *ubanu } & l u \text {-le } & \text { many-ik-a-a } \\
\text { 11eucalyptus } & \text { 11SA-PST } & \text { cut-STAT-FV-HAB }
\end{array}
$$

It has further been observed that middle sentences in Kiwoso involve the habitual aspect which denotes the generic meaning of these constructions. Therefore, the sentences for anticausatives and middles are similar, except that middles cannot be distinguished in terms of (im-)perfective event interpretation because they denote generic statements. In Kiwoso, constructions which are regarded as dispositional middles appear only in the simple present tense in combination with the stative suffix $-i k$ - and the habitual morpheme $-a$, which is obligatory in middle constructions in Kiwoso. Therefore, distinct from the anticausative and the passive constructions, middle sentences involve habitual aspect which form the functional head in Kiwoso middle constructions. An abstract structure in (37), presented in Figure 4 demonstrates. 


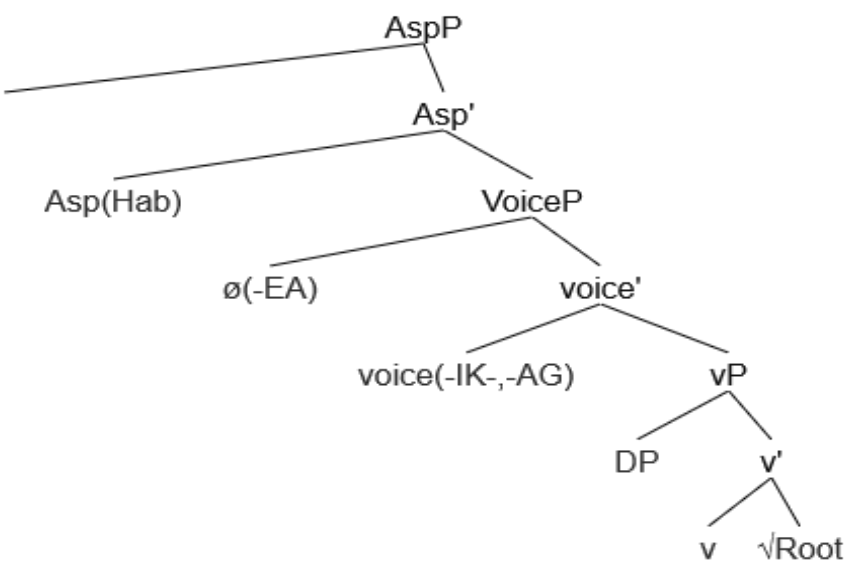

Figure 4: Decomposition of middle constructions in Kiwoso

It has been mentioned that distinct from the passive and anticausative verb constructions, middle sentences involve habitual morphemes which form the aspectual functional head. Similarly to anticausatives, the suffix - $i k$ - marks middle alternates in addition to the habitual morpheme $-a-$. The $-i k$ - form is also regarded as a morphological indication of the absence of external arguments. Middle constructions in Kiwoso are similar to anticausative sentences in that both involve non-agentive features with respect to the semantic feature of the voice, i.e. (Voice $[-A G]$ ) (see Figure 4).

\section{Conclusion}

This paper examined the properties of externally caused change of state verbs in Kiwoso in relation to the lexical-semantics and syntax interface of (anti-)causative alternations. The paper attempted to answer three questions: 1) what are the meaning components that determine the behavior of individual verbs in anticausative alternations? 2) what are the properties of external arguments of (anti-)causatives thematically and syntactically? 3) what makes anticausatives similar to, or different from, other transitivity alternation constructions such as the passive and the middle?

The data examined in this paper demonstrates that externally caused verbs in Kiwoso widely alternate and that alternation is determined by encyclopaedic properties of the individual verb root and its combination with different functional heads. It was established that Kiwoso change of state verbs show different argument realization patterns depending on the conceptualization of eventualities. For example, verbs that denote human-driven activities such as cook, cut, and the verb grind cannot realize natural forces as their external arguments, while break and bend verbs can license such arguments. With regard to external argument realizations, it has been established that verbs that describe non-human-driven activities realize agent, instrument, as well as causers as their external arguments.

The analysis of the data demonstrates that all three external arguments expressed in causative sentences appear as implicit arguments in passive constructions, and these arguments can be reintroduced via a prepositional $n a$-phrase 'by-phrase'. However, anticausative constructions are compatible with an agentive phrase, an instrument, and a causer if they are introduced by a ko-phrase, and interpreted as event modifiers rather than event participants (i.e. arguments). 
It has been established that passive and anticausative constructions differ from middle sentences in that middles have a generic interpretation, and unlike passives and anticausatives, they lack specific time references. Furthermore, unlike anticausative and passive sentences, the subject of any middle constructions is conceptualized as having specific characteristics that make the prescribed eventualities generic.

\section{Abbreviations}

1, 2, $3 \ldots$ - noun class numbers; ADJ - adjective; ADV - adverbial; CAUS - causative; FV final vowel; HAB - habitual; INIT - initial element; LOC - locative; PASS - passive; PERF - perfect; PP - prepositional phrase; PST - past tense; SA - subject agreement; STAT stative.

\section{References}

Alexiadou, A. and F. Schäfer. 2006. Instrument subjects are agents or causers. In D. Baumer, D. Montero and M. Scanlon (eds.) 25th West Coast Conference on Formal Linguistics. Somerville: Cascadilla Proceedings Project. pp. 40-48.

Alexiadou, A. 2010. On the morphosyntax of (anti)causative verbs. In M. Rappaport Hovav, E. Dorin and I. Sichel (eds.) Lexical Semantics, Syntax, and Event Structure. Oxford: Oxford University Press. pp. 177-203. https://doi.org/10.1093/acprof:oso/9780199544325.003.0009

Alexiadou, A., E. Anagnostopoulou and F. Schäfer. 2006. The properties of anticausatives crosslinguistically. In M. Frascarelli (ed.) Phases of Interpretation. Berlin: De Gruyter Mouton. pp.175-199. https://doi.org/10.1515/9783110197723.4.187

Alexiadou, A., E. Anagnostopoulou and F. Schäfer. 2015. External Arguments in Transitivity Alternations: A Layering Approach. Oxford: Oxford University Press. https://doi.org/10.1093/acprof:oso/9780199571949.001.0001

Dom, S., L. Kulikov and K. Bostoen. 2016. The middle as a voice category in Bantu: Setting the stage for further research. Lingua Posnaniensis 58(2): 129-149. https://doi.org/10.1515/linpo-2016-0012

Dom, S., L. Kulikov and K. Bostoen. 2018. Valency-decreasing derivations and quasimiddles in Bantu: A typological perspective. Southern African Linguistics and Applied Language Studies 36(3): 165-173. https://doi.org/10.2989/16073614.2018.1552164

Dubinsky, S. and S. Simango. 1996. Passive and stative in Chichewa: evidence for modular distinctions in grammar. Language 72: 749-781. https://doi.org/10.2307/416101

Fernando, M. 2013. The Causative and Anticausative Alternation in Kikongo (Kizombo). $\mathrm{PhD}$ dissertation, Stellenbosch University. 
Hyman, L. 2003. Suffix ordering in Bantu: A morphocentric Approach. In G. Booijand and J. van Marle (eds.) Yearbook of Morphology 2002. Dordrecht: Kluwer Academic Publishers. pp. 245-281. https://doi.org/10.1007/0-306-48223-1_8

Jerro, K. 2018. Change-of-state paradigms and the middle in Kinyarwanda. Southern African Linguistics and Applied Language Studies 36(3): 235-260. https://doi.org/10.2989/ $\underline{16073614.2018 .1552168}$

Kallulli, D. 2007. Rethinking the Passive/Anticausative distinction. Linguistic Inquiry 38(4): 770-780. https://doi.org/10.1162/ling.2007.38.4.770

Khumalo, L. 2009. The passive and stative constructions in Ndebele: A comparative analysis. Nordic Journal of African Studies 18(2): 154-174.

Levin, B. 1993. English Verb Classes and Alternation: A Preliminary Investigation. Chicago: University of Chicago Press.

Levin, B. and M. Rappaport Hovav. 1995. Unaccusativity: At the Syntax-Lexical Semantics Interface. Cambridge: MIT Press. https://doi.org/10.1017/s0022226796276571

Lusekelo, A. 2008. A descriptive account of the Bantu verbal extensions in Kinyakyusa. Journal of Research in African Languages and Linguistics 8: 83-116.

Lusekelo, A. 2012. Inflectional and Derivational Morphology in Optimality Theory: Multiple Object Nouns and Co-occurrence of Verbal Extensions in Kinyakyusa. PhD dissertation, University of Botswana.

Mchombo, S. 2004. The Syntax of Chichewa. Cambridge: Cambridge University Press.

Mchombo, S. 2007. Argument binding and morphology in Chichewa. In F. Hoyl, N. Seifert, A. Teodorescu and J. White (eds.) Morphosyntax of Underrepresented Languages. Stanford: CSLI Publications. pp. 203-221.

Mkude, D. 2005. The Passive Construction in Swahili Volume 4. Tokyo: Research Institute for Languages and Culture of Asia and Africa (ILCAA).

Moshi, L. 1998. Word order in multiple object constructions in KiVunjo-chaga. Journal of African Languages and Linguistics 19: 137-152. https://doi.org/10.1515/jall.1998.19.2.137

Petzell, M. 2008. The Kagulu Language of Tanzania. Köln: Rudiger Kopper Verlag.

Rugemalira, J. 1995. Verb extensions in Runyambo. Afrikanistische Arbeitspapiere 41: 5187.

Schäfer, F. 2009. The causative alternation. Language and Linguistics Compass 3(2): 641681. https://doi.org/10.1111/j.1749-818x.2009.00127.x 
Seidl, A. and A. Dimitriadis. 2003. Statives and reciprocal morphology in Swahili. Typologie des langues d'Afrique and universaux de la grammaire 1: 239-284. 